\title{
THE EFFECT OF AVOCADO SEED EXTRACT (PERSEA AMERICANA) ON CARBIDE INDUCED HEPATOXICITY IN
}

\section{ADULT WISTAR RATS}

Victoria Nneoma Okpala ${ }^{1}$, Damian Nnabuihe Ezejindu ${ }^{1}$, Joseph Ifeanyi Brian-D ${ }^{2 *}$, Mark Matthew Edet ${ }^{2,3}$

${ }^{1}$ Department of human anatomy, Nnamdi Azikiwe University, Nnewi, Nigeria

${ }^{2}$ Centre for health and allied legal and demographical development research and training (CHALADDRAT), Nnamdi Azikiwe University, Awka, Nigeria.

${ }^{3}$ Department of human biochemistry, Nnamdi Azikiwe University, Nnewi, Nigeria

\section{*Corresponding Author:}

Prof. Joseph Ifeanyi Brian-D Adinma,

Department of obstetrics and gynecology,

Nnamdi Azikiwe University and Teaching Hospital, Nnewi, Nigeria.

+2348037080814; email: br.adinma@unizik.edu.ng or brianadinma@yahoo.com

\begin{abstract}
Context: Persea Americana is reported to have medicinal value. Calcium Carbide $\left(\mathrm{CaC}_{2}\right)$, a fruit-ripening agent, has been shown to be toxic to body organs.

Objective: To determine the effect of avocado seed extract (ASE) on $\mathrm{CaC}_{2}$-induced hepatotoxicity in rats.

Methodology: Four experimental groups, each of 5 adult wistar rats were fed respectively with normal diets (group A); 250mg/kg ASE (group B); 100mg/kg CaC 2 (group C); combination of $100 \mathrm{mg} / \mathrm{kg} \mathrm{CaC} 2$ and $250 \mathrm{mg} / \mathrm{kg} \mathrm{ASE}$ - group D. Changes in the rats' behaviours, body weights, and liver function were assessed over 21 days. Data were analyzed using SPSS. The cumulated rat weights, rat liver weights and serum liver enzyme levels for groups B, C, and D rats were compared to group A.
\end{abstract}

Results: Abnormal behavior was most observed in group $\mathrm{C}$ rats. Rats in group A showed a significant increase in weight before and three weeks following administration of feeds while 
rats in groups B, C, and D showed significant decrease in weight - more marked in group C rats. Only the mean liver weights of rats in group $\mathrm{C}$ showed significant decrease compared to that in group $\mathrm{A}, \mathrm{p}=0.001$. Similarly, only the cumulated liver enzyme levels of rats in group $\mathrm{C}$ demonstrated significant increase when compared to group A rats - indicating hepatotoxicity.

\section{Conclusion}

In this study, hepatotoxicity occurred in $\mathrm{CaC}_{2}$-administered rats. However, the combination of $\mathrm{CaC}_{2}$ and $\mathrm{ASE}$ showed no liver toxicity indicating a mitigating effect of $\mathrm{ASE}$ to $\mathrm{CaC}_{2}$-induced hepatotoxicity.

Keywords: Avocado; Calcium carbide; hepatotoxicity; liver; Persea Americana; seed extract; toxicity; wistar rats.

\section{Introduction}

Leaves, peels, and seeds from fruits and other agro products, in the past have been regarded as 'wastes,' constituting environmental pollutants. In recent times however, they have been observed to be useful not only as nutrient, on account of their antioxidant properties but also medicinal, exhibiting immense therapeutic values in the treatment of various ailments including cancers. ${ }^{1-3}$ Persea Americana (PA) mill, commonly known as avocado pear, is an evergreen tree belonging to the family Lauraceae as well as the genus, persea. It was originally grown in Guatemala and Mexico but it is now grown in the tropics and sub-tropics ${ }^{4}$, Nigeria inclusive. Amongst the Igbo-speaking group of southeastern Nigeria, the fruit is known as Ube Oyibo ${ }^{5}$; while amongst the yorubas of southwest Nigeria it's called "Igba or apoka"." Following the consumption of the fleshy part of avocado pear, the seed is oftentimes thrown away but on some occasion may be ground, milled or incorporated into foods for consumption as medicinal preparation - believed to be useful in the treatment of inflammations, hypertension, diabetes, and cancer. ${ }^{4,7}$

Calcium carbide is a group 14 alkaline earth compounds which in its pure form is colorless ${ }^{8}$. It is indiscriminately used to hasten the ripening of fruits, and is believed to have toxic effects on some tissues/organs such as liver or kidney, thereby rendering it a threat to the health of human consumers. ${ }^{9}$

This study has been undertaken to evaluate the effect of avocado seed extract on carbide induced hepatotoxicity in adult wistar rats. The study is important in that it will definitely determine whether or not calcium carbide has any toxic effect on the liver of adult wistar rats and also whether or not avocado seed extract can neutralize or ameliorate any toxic effect induced by the calcium carbide.

\section{Materials and method}

This study was carried out in the laboratory unit of the department of Anatomy, Nnamdi Azikiwe

University, Nnewi, Anambra state southeastern Nigeria. Ethical approval was obtained from the 
ethics committee of faculty of basic medical sciences of the university. All chemicals and solvent materials including some equipment used in this study were obtained from the aforementioned laboratory. Thirty pieces of avocado pear bought from Nkwo market in Nnewi (June 2018) were allowed to ripe. Each was cut into halves and the seed extracted using seed extractor. The extracted seed was washed in clean tap water; sliced into pieces using manual grater and subsequently dried under the sun for 3 days. ${ }^{4}$ A laboratory miller was used to grind the dried seed into flour. The Test for acute toxicity from calcium carbide was carried out according to Dietrich Lorke ${ }^{10}$ method (1983).

\section{Experimental animals and design}

Twenty apparently healthy albino wistar rats weighing between 100 and $180 \mathrm{~g}$ were bought from a local farm at Nnewi and moved to the site of the experiment. The rats were divided into 4 groups (each of 5 rats) and allowed to acclimatize for a period of two weeks during which they were fed with known weight of about $100 \mathrm{~g}$ daily of normal growers mesh (a product of Premier Feed Mills Co. Limited in Sapele, Delta State, Nigeria) and water. The rats were weighed before the administration of the test substances commenced and thereafter weighed once weekly - on fridays of the week, before feeding. The administration of the avocado seed extract was done as follows: Group A - the control group received only water and feed daily for three weeks; group B - received only $250 \mathrm{mg} / \mathrm{kg}$ body weight daily of avocado seed extract for three weeks; Group C - received only $100 \mathrm{mg} / \mathrm{kg}$ body weight daily of calcium carbide for three weeks; while group D were given a combination of $100 \mathrm{mg} / \mathrm{kg}$ and $250 \mathrm{mg} / \mathrm{kg}$ body weight daily respectively of calcium carbide and avocado seed extract for three weeks. All administrations were made orally with syringes and cannula. The rats were sacrificed after 21 days of administration by cervical dislocation. Following the sacrifice, blood sample of each rats collected from the heart with the 
use of a syringe was transferred to a clean non-anti-coagulated polystyrene tube, allowed to clot, and centrifuged at $3000 \mathrm{rpm}$ for $5 \mathrm{~min}$. The serum collected was then stored in a refrigerator for use in the experiment. The serum sample was also assayed biochemically for marker enzymes aspartate aminotransferase (AST), alanine aminotransferase (ALT) ${ }^{11}$, and alkaline phosphatase (ALP). ${ }^{12}$ The isolated liver tissue of the rats were washed with normal saline, blotted with filter paper, and subjected to weighing with analytical weighing balance.

\section{Statistical analysis}

Statistical analysis was done using SPSS software version 23 (Windows IBM Cooperation). Analysis of variance (ANOVA) - followed by multiple comparism with Fisher's LSD Post HOC test (where necessary), and student's t-test was used in comparison of means of bio-functional parameters with $\mathrm{P}<0.05$ considered to be statistically significant.

\section{RESULTS}

The distribution by physical and behavioural features of rats in the various groups before and following the administration of avocado seed extract and calcium carbide is shown in table 1. During acclimatization period, the rats in all the groups showed healthy features (with smoothly laid hairs on their skin, pinkish eyes, normal skin colour and increase in size). Following the administration of the test substances, group A showed no clinical signs while the remaining groups had Labor breathing, staggering gait and decreased food intake which was more pronounced in rats in group $\mathrm{C}$.

Table 1: Distribution by physical and behavioural features of rats in the various groups before and following the administration of avocado seed extract and calcium carbide

\section{Group}

Clinical features (labored breathing, staggering gait, decreased food intake) 


\begin{tabular}{|l|l|l|}
\hline & $\begin{array}{l}\text { During } \\
\text { acclimatization } \\
\mathbf{( 2} \text { weeks) }\end{array}$ & $\begin{array}{l}\text { Following administration of } \\
\text { avocado pears/calcium carbide } \\
\text { (3 weeks) }\end{array}$ \\
\hline A (rats fed with only water and feed) & Nil & Nil \\
\hline B (rats fed with PA extract alone) & Nil & Mild \\
\hline C (rats fed with $\mathrm{CaC}_{2}$ alone) & Nil & Severe \\
\hline D (rats fed with $\mathrm{PA}$ and $\mathrm{CaC}_{2}$ ) & Nil & Moderate \\
\hline
\end{tabular}

Table 2 shows the distribution of the mean weight of the rats in the various groups before and after the administration of test substance. There was a significant increase between the initial and final mean weight of the rats in group A while the mean weight of the rats in groups $\mathrm{B}, \mathrm{C}$, and D showed a significant decrease between the initial and the final weight, $\mathrm{p}<0.05$.

Table 2: Distribution of the mean weight of the rats in the various groups before and after the administration of test substance

\begin{tabular}{llrlll}
\hline Body weight (g) & & MEAN & \pm SEM P-VALUE & T-Value \\
\hline Group A & Initial & 125.00 & \pm 2.88 & & \\
& Final & 142.00 & \pm 2.50 & $0.006^{*}$ & -7.000 \\
Group B & Initial & 180.00 & \pm 0.00 & & \\
& Final & 167.00 & \pm 2.50 & $0.001^{*}$ & -13.000 \\
Group C & Initial & 140.00 & \pm 0.00 & & \\
& Final & 123.00 & \pm 9.57 & $0.038^{*}$ & -0.522 \\
Group D & Initial & 158.00 & \pm 0.00 & & \\
& Final & 130.00 & \pm 13.54 & $0.014^{*}$ & -0.739 \\
\hline
\end{tabular}

Data were analyzed using Student dependent T-test and values were considered significant at $\mathrm{P}<0.05$. ${ }^{*} \mathrm{P}<0.05$ means significant.

The distribution by experimental rat groups for their mean liver weights is shown in table 3 . There is no significant difference in the mean liver weights between the rats in group B 
(3.56 \pm 0.39$)$ and rats in group D (3.86 \pm 0.04$)$ when compared to that in group A, $3.42 \pm 0.08-(\mathrm{p}$ $=0.076$ apiece). However there was a significant increase in liver weight for the rats in group $\mathrm{C}$ $(6.62 \pm 0.20 \mathrm{~g})$ compared to the normal (group A), $3.42 \pm 0.08(\mathrm{p}=0.001)$.

Table 3: Distribution by experimental rat groups for their mean liver weights

\begin{tabular}{llllll}
\hline & & & & & \\
& & MEAN & \pm SEM & P-VALUE & F-VALUE \\
\hline Relative Liver weight (g) & Group A & 3.42 & \pm 0.08 & & \\
& Group B & 3.56 & \pm 0.39 & 0.076 & 1.965 \\
& Group C & 6.62 & \pm 0.20 & $0.001^{*}$ & \\
& Group D & 3.86 & \pm 0.04 & 0.076 & \\
\hline
\end{tabular}

Data were analyzed using One way ANOVA followed by Post HOC Fisher's LSD multiple comparism, and data were considered significant at $\mathrm{P}<0.05$. $* \mathrm{P}<0.05$ means significant and $\mathrm{P}>0.05$ means not significant.

Table 4 shows the distribution by mean levels of serum liver enzymes for the various groups - B, C, D compared to normal group A. Aspartate transaminase enzyme levels did not show any significant difference between the rats in group B and D compared to those in group A. However there was a significant increase in the levels for $\mathrm{CaC} 2$-administered rats. Similarly, there was slightly higher but insignificant levels of alanine transaminase enzymes for the rats in group B and D compared to those in A. This is in contradistinction to the level of enzyme for the rats in group $\mathrm{C}$ which showed a highly significant increase. The same pattern has also been exhibited for the levels of alkaline phosphatase enzyme which showed a significant increase only for rats in group $\mathrm{C}$ in contradistinction to those in group B and group D that showed no significant increase when compared to the levels for rats in group A.

Table 4: Distribution by mean levels of serum liver enzymes for the various groups - B, C, D compared to normal group A

\begin{tabular}{lllll} 
& & MEAN & \pm SEM & P-VALUE \\
\hline Aspartate & Group A & 25.00 & \pm 6.35 & \\
Aminotransferase (U/L) & Group B & 26.20 & \pm 0.57 & 0.060 \\
& Group C & 39.00 & \pm 3.46 & $0.000^{*}$ \\
& group D & 27.50 & \pm 0.58 & 0.076 \\
\hline
\end{tabular}




\begin{tabular}{|c|c|c|c|c|c|}
\hline \multirow{4}{*}{$\begin{array}{l}\text { Alanine } \\
(\mathrm{U} / \mathrm{L})\end{array}$} & \multirow[t]{4}{*}{ Transaminase } & Group A & 27.25 & \multicolumn{2}{|l|}{$0 \pm 0.58$} \\
\hline & & Group B & 28.33 & \pm 0.33 & 0.051 \\
\hline & & Group C & 40.66 & \pm 0.88 & $0.000 *$ \\
\hline & & group D & 29.33 & \pm 4.91 & 0.062 \\
\hline \multirow{4}{*}{$\begin{array}{l}\text { Alkaline } \\
(\mathrm{U} / \mathrm{L})\end{array}$} & Phosphatase & Group A & 32.33 & \pm 2.33 & \\
\hline & & Group B & 33.60 & \pm 74.44 & 0.060 \\
\hline & & Group C & 51.66 & \pm 10.13 & $0.003 *$ \\
\hline & & group D & 36.00 & \pm 85.28 & 0.053 \\
\hline
\end{tabular}

\section{Discussion}

In a comprehensive systematic review of the various components of avocado pear - peels, flesh, and seed on metabolic syndrome (a group of risk factors that include elevated blood glucose, hypertension, dislipidemia, and obesity - capable of resulting in type 2 diabetes mellitus and cardiovascular disease), Tabeshpour et al reported that avocado had significant effect on lipid profile regulation. The study also observed that avocado pear can be taken as dietary supplement in the treatment of metabolic syndrome. ${ }^{13}$ Avocado seed extract has been used in this study to elicit its bio-clinical effect on adult wistar rats and also determine whether or not its intake mitigates the toxic effect of calcium carbide on the rat liver - considered to be the major metabolic site of the animal.

There was observed alterations in both the physical features and behavioural pattern of the rats following the administration of the study test substances. Labored breathing, staggering gait, and reduced food intake were the main observed features most marked, or severe, amongst the group of rats fed with calcium carbide alone; moderately observed amongst that fed with calcium carbide and PA extract; and only mildly exhibited by the rats fed with avocado seed extract alone. These observations are similar to the clinical features seen in humans with liver diseases who often times present with loss of appetite, body weakness, and weight loss over time ${ }^{14}$, and suggests that the test substances, particularly calcium carbide (which exhibited the most marked manifestation of these features) may in fact have some toxic effect on the rat liver. Reduction in weight was also shown to a lower extent in rats fed with avocado seed extract alone and even those fed with calcium carbide combined with PA extract. This contrast with the observation made in the rats in group A who were given normal feeds and showed a significant weight gain 
post feed compared to before. The hypoglycemic effect of avocado seed extract manifested in this study has been similarly reported in previous studies. ${ }^{15,16}$ It has been shown in rats that aqueous concentration of avocado seed extract caused a significant decline in serum glucose concentration thereby exhibiting antihyperglycemic and hypoglycemic characteristics that portray its immense potentials for use in the treatment of diabetes. ${ }^{17}$ In a randomized clinical study of 26 healthy subjects, Sabate et al concluded that the presence of D-mannoheptulose in avocado extract is likely to be responsible for its hypoglycemic effects through its inhibition of hexokinase activities and ultimate reduction of glycolysis. ${ }^{18}$

This study demonstrated no significant difference in mean liver weight between the rats in group B () and D (), compared to those in group A. however, there was a significantly increased liver weight for the rats in group $\mathrm{C}$ - treated with calcium carbide alone. This suggests that calcium carbide may have a toxic effect on the liver, liver enlargement being a common clinical feature of liver disease. The fact that the same dose of calcium carbide combined with PA extract did not cause any significant increase in mean liver weight may suggest that pear extract may in fact have a mitigating effect on the impact of calcium carbide on rat liver - thereby probably assigning potential therapeutic properties to the Persea American seed extract. Ample evidence exist to show that in spite of the perceived therapeutic properties ascribable to PA on account of its enormous nutrient contents, avocado poising does occur in various animals - fish, cats, dogs, cattle, and rats following consumption of different components of the avocado - leaves, fruits, stem, bark and pit in variable quantities. ${ }^{19,20}$ This underscores the necessity for more comprehensive and painstaking research towards determining appropriate dosages of avocado extract compatible with safety and optimum effectiveness. Liver enzymes are important biochemical components of liver function test (LFT). Aspartate and alanine transaminase enzymes are major mirrors of derangement in function of hepatocytes, while alkaline phosphatase enzymes indicate obstruction. ${ }^{21}$ This study shows that the various liver enzymes exhibited no significant derangement for the rats treated with avocado extracts alone and those treated with avocado extracts in combination with calcium carbide when compared to the untreated rats. This suggests that avocado seed extract has no toxic consequences on the liver. The rats treated with calcium carbide however showed significant increase in the levels of these enzymes suggesting that the chemical may indeed have a toxic effect on the liver. The fact that the enzyme levels were not significantly raised for the rats in group D treated with a combination 
of calcium carbide and avocado pear indicate that avocado pear extract may, as observed with the liver have a mitigating effect on the toxicity of the calcium carbide, thereby suggesting as observed earlier that avocado pear may in fact have protective medicinal properties.

\section{Conclusion and recommendation}

Avocado pear has been a time-acclaimed fruits of which it's various components including leaf, fruits, stem, bark, and seed have been reported to be useful for their antioxidant and other therapeutic values. This study shows that the seed extract has an effect in the lowering of the weight of the rats which is believed to be on account of its antiglycemic and hypoglycemic properties. The study also demonstrates that the seed extract has no significant toxic effect on the liver evident from the insignificant deleterious effect it has in liver weights and liver enzyme levels. $\mathrm{CaC} 2$ on the other hand, a substance used often to effect premature ripening of fruits has been demonstrated in this study to significantly affect rat body weight and rat liver function evidenced from its effect on liver enlargement as well as derangements of liver function from significantly elevated liver enzymes. More importantly, the study has demonstrated that when administered in combination with calcium carbide, liver morphology and liver function were not significantly affected and this suggests therefore that avocado extract mitigates the deleterious effect of $\mathrm{CaC} 2$ on rat liver thereby assigning potential therapeutic properties to avocado seed extract. The fact that some reports have demonstrated poisoning, sometimes with lethal outcome, to some animals unequivocally suggest the need for further research into the various components of avocado to a certain appropriate dosages that will enhance their effectiveness and use on humans.

Conflict of interest: There is no conflict of interest with regards to the publication of this work.

\section{Author contribution}

Victoria Nneoma Okpala: project administration, resources, original draft preparation; Damian Nnabuihe Ezejindu: project administration, supervision; Joseph Ifeanyi Brian-D Adinma: writing - original draft preparation, review and editing; Mark Matthew Edet: writing - original draft preparation, review and editing, data curation and visualization - where applicable.

\section{References}


1. Abdel-Moneim A, Ahmed OM, Fahim HI, Mohamed EE. The preventive effects of Avocado fruit and seed extracts on cardio-nephrotoxicity induced by diethylnitrosamine/2-acetylaminoflurine in Wistar Rats. Basic Sci Med [Internet]. 2017;6(1):4-13. Available from: http://journal.sapub.org/medicine

2. Egbonu ACC, Chukwu EM, Chibuzor W, Obi E, Ezenwafor NR, Simon CU, et al. Artemether-lumefantrine Improved superoxide dismutase co-regulation related antioxidant defense in monosodium glutamate-induced oxidative stress in Rats. Asian J Biochem. 2020;15(2):42-9.

3. Ejiofor NC, Ezeagu IE, et al. Determination of the Chemical Composition of Avocado (Persea Americana) Seed. Adv Food Technol Nutr Sci - Open J. 2018;SE(2):S51-5.

4. Egbuonu ACC, Opara CI, Akachukwu D, Onyedikach UB. Effect of Ethanolic Extract of Avocado Pear (Persea americana) Seed on Normal and Monosodium Glutamatecompromised Rats' Hepatic Histo-morphology and Serum Bio-functional Parameters. Res J Environ Sci. 2018;12(2):53-62.

5. Dreher ML, Davenport AJ. Hass avocado composition and potential health effects. Crit Rev Food Sci Nutr. 2013;53(7):738-50.

6. Ezuruike UF, Prieto JM. The use of plants in the traditional management of diabetes in Nigeria: pharmacological and toxicological considerations. J Ethnopharmacol. 2014 Sep;155(2):857-924.

7. Alhassan AJ, Sule MS, Atiku MK, Wudil AM, Abubakar H, Mohammed SA. Effects of aqueous avocado pear (Persea americana) seed extract on alloxan induced diabetes rats. Greener J Med Sci. 2012;2(1):5-11.

8. Ropp RC. Chapter 5 - Group 14 (C, Si, Ge, Sn, and Pb) Alkaline Earth Compounds. In: Ropp RCBT-E of the AEC, editor. Encyclopedia of the Alkaline Earth Compounds [Internet]. Amsterdam: Elsevier; 2013. p. 351-480. Available from: https://www.sciencedirect.com/science/article/pii/B9780444595508000053

9. Emere MC, Aina v O, Isechab M, Baba BA. Effects of calcium carbide on some 
biochemical parameters of liver and kidney of Wister albino rats. J Pharm Allied Sci. 2018;15(3):2810-9.

10. Lorke D. A new approach to practical acute toxicity testing. Arch Toxicol. 1983 Dec;54(4):275-87.

11. Lieber CS. Biochemical factors in alcoholic liver disease. Semin Liver Dis [Internet]. 1993;13(2):136-53. Available from: http://europepmc.org/abstract/MED/8337602

12. Tietz NW, Burtis CA, Duncan P, Ervin K, Petitclerc CJ, Rinker AD, et al. A reference method for measurement of alkaline phosphatase activity in human serum. Clin Chem. 1983 May;29(5):751-61.

13. Tabeshpour J, Razavi BM, Hosseinzadeh H. Effects of Avocado (Persea americana) on Metabolic Syndrome: A Comprehensive Systematic Review. Phytother Res. 2017 Jun;31(6):819-37.

14. Mallik S, Sarkar K, Rahman M, Haldar SN. Clinical and etiological study on chronic liver diseases. Int J Contemp Med Surg Radiol. 2018;3(2):77-80.

15. Kopec RE, Cooperstone JL, Schweiggert RM, Young GS, Harrison EH, Francis DM, et al. Avocado consumption enhances human postprandial provitamin A absorption and conversion from a novel high- $\beta$-carotene tomato sauce and from carrots. J Nutr. 2014 Aug;144(8):1158-66.

16. Park E, Edirisinghe I, Burton-Freeman B. Avocado fruit on postprandial markers of cardio-metabolic risk: a randomized controlled dose response trial in overweight and obese men and women. Vol. 10, Nutrients. 2018.

17. Ezejiofor AN, Okorie A, Orisakwe OE. Hypoglycaemic and tissue-protective effects of the aqueous extract of persea americana seeds on alloxan-induced albino rats. Malays $\mathbf{J}$ Med Sci. 2013 Oct;20(5):31-9.

18. Sabaté J, Wien M, Haddad E. Post-ingestive effects of avocados in meals on satiety and gastric hormone blood levels. Hum Heal Nut. 2015;459-461. 
19. Clipsham R. Avocado Toxicity [Internet]. 1987 [cited 2021 May 18]. Available from: http://kgkat.tripod.com/avocado.html

20. Oelrichs PB, Ng JC, Seawright AA, Ward A, Schäffeler L, MacLeod JK. Isolation and identification of a compound from avocado (Persea americana) leaves which causes necrosis of the acinar epithelium of the lactating mammary gland and the myocardium. Nat Toxins. 1995;3(5):344-9.

21. Limdi JK, Hyde GM. Evaluation of abnormal liver function tests. Postgrad Med J [Internet]. 2003 Jun 1;79(932):307 LP - 312. Available from: http://pmj.bmj.com/content/79/932/307.abstract 